\title{
ÉPOCAS DE PODA E USO DA IRRIGAÇÃO EM FIGUEIRA ‘ROXO DE VALINHOS' NA REGIÃO DE BOTUCATU, SP (1)
}

\author{
SARITA LEONEL $\left({ }^{2, *}\right)$; MARCO ANTONIO TECCHIO $\left({ }^{3}\right)$
}

\begin{abstract}
RESUMO
O trabalho teve como objetivo avaliar a poda de frutificação da figueira 'Roxo de Valinhos' em julho, agosto, setembro e outubro, com e sem o uso de irrigação complementar, nos ciclos de 2004/ 2005 e 2005/2006, em experimento realizado em Botucatu (SP). O delineamento experimental adotado foi o de parcelas subdivididas, com cinco repetições, sendo as parcelas correspondentes aos tratamentos com e sem irrigação e as subparcelas, as quatro épocas de poda realizadas. Foram avaliadas características de crescimento, produtividade e sazonalidade. Pelos resultados, permitiu-se concluir que agosto, com o uso de irrigação complementar, foi o mês mais favorável para a realização da poda da figueira, no município de Botucatu (SP), proporcionando maior crescimento dos ramos, e maiores produtividades médias no ensaio tanto no ciclo agrícola 2004/2005 (5,13 t ha-1), quanto no de 2005/2006 $\left(5,82 \mathrm{t} \mathrm{ha}^{-1}\right)$. Em condições não irrigadas, melhores respostas foram obtidas com poda em julho, agosto e setembro de 2004 / 05 e julho e agosto de 2005 / 06 . O período produtivo da figueira no município estendeu-se de dezembro a abril, e com o uso de irrigação houve maior número de colheitas e ampliação do ciclo produtivo.
\end{abstract}

Palavras-chave: Ficus carica L., crescimento, produtividade, sazonalidade.

\section{ABSTRACT \\ PRUNING TIME AND IRRIGATION ON THE FIG TREES ‘ROXO DE VALINHOS', IN THE BOTUCATU REGION, STATE OF SÃO PAULO, BRAZIL}

The research had the purpose to determine the effects of pruning time during July, August, September and October of 2004 and 2005 years, with and without irrigation, in the fig trees 'Roxo de Valinhos'. The experimental orchard was located in Botucatu region State of São Paulo, Brazil. The experimental design was in split plots with five replications, being the plots consisted in the treatments with and without irrigation and the subplots was composed of pruning made during the months. It were measured the growing, yield and the crop period. These characteristics were utilized to evaluate the irrigation requirement. August was the best time to the fig trees pruning with irrigation, enhancing the growth and yield (5.13 $\mathrm{t} \mathrm{ha}^{-1}$ in 2004/ 05 and $5.82 \mathrm{t} \mathrm{ha}^{-1}$ in 2005/06). Without irrigation, the pruning made at July, August and September (2004/05) and in July and August (2005/06) produced better results. The crop period of fig trees extended from December up to April. The irrigation enhanced the harvest number and the crop period.

Key words: Ficus carica L., growth, yield, crop period.

(1) Recebido para publicação em 5 de março 2008 e aceito em 21 de dezembro de 2010.

(²) UNESP - Faculdade de Ciências Agronômicas, Departamento de Produção Vegetal, Caixa Postal 237, $18610-307$ Botucatu (SP), Brasil. E-mail: sarinel@fca.unesp.br $\left(^{*}\right)$ Autora correspondente.

$\left(^{3}\right)$ Centro Avançado de Pesquisa Tecnologia do Agronegócio de Frutas, IAC, 13214-820 Jundiaí (SP), Brasil. E-mail: tecchio@iac.sp.gov.br. 


\section{INTRODUÇÃO}

A cultura da figueira é interessante para o Brasil, hoje o segundo maior exportador de frutas in natura do mundo, pelas possibilidades da produção brasileira coincidir com a entressafra do mercado mundial no hemisfério norte. Para o Estado de São Paulo, a cultura está concentrada na região de ValinhosCampinas e o cultivo caracteriza-se por uma atividade predominantemente familiar, em pequenas áreas (média de $0,7 \mathrm{ha} /$ propriedade), utilizando grande quantidade de mão-de-obra (Penteado e Franco, 1997). Conforme os autores, por ser originária da região mediterrânica, onde predomina clima subtropical temperado, a figueira é uma planta que se adapta aos diferentes climas, sendo cultivada em regiões subtropicais, temperadas e inclusive, em função de sua baixa exigência em frio, a cultura está se expandindo para áreasnão tradicionais, no planalto paulista, em consequência da supervalorização das terras e da grande urbanização da região produtora original.

A cultura exige, no período vegetativo, chuvas frequentes e bem distribuídas. A média pluviométrica de $1.200 \mathrm{~mm}$ anuais e o emprego de cobertura do solo com palha de capim ou bagaço de cana-de-açúcar tem permitido preservar o equilíbrio e a umidade do solo, fatores fundamentais para o adequado desenvolvimento da figueira. Em locais com precipitações irregulares, inclusive as pequenas estiagens são sentidas pela planta, causando queda de folhas e prejuízos da produção, sendo em decorrência, aconselhável a irrigação (RIGITANO, 1964; CorrêA e SANTOS, 1999).

CorRÊA e SANTOS (1999) esclarecem que os cultivos comerciais no Brasil se estabeleceram em meados do século 20, com muitos problemas com o ataque de brocas e ferrugem, prejudicando o desenvolvimento das plantas, dando origem a frutos pequenos e atrofiados e a principal colheita anual nunca ultrapassava o mês de janeiro (RIGITANO, 1964). Visando solucionar esse problema, foi adotada a poda drástica, com destruição completa dos ramos da poda, sendo essa indispensável medida fitossanitária (CoRrêA e SANTOS, 1999). Segundo MAIORANO et al. (1997), a figueira se adapta muito bem ao sistema de poda drástica ou constante, fazendo com que as plantas permaneçam em estado arbustivo.

Diferentes trabalhos de pesquisa com manejo da poda da figueira foram e continuam sendo realizados no Brasil (BRIGHENTI, 1980; SAMPAIO et al.,1981; NorBERTO et al., 2001; GONÇALVES et al.,2006), e todos eles fundamentam-se nas seguintes premissas: o curto período de conservação do figo 'Roxo de Valinhos' ao natural; as necessidades da indústria de figo verde que precisa de matéria-prima o ano todo; a possibilidade da dilatação no período de oferta da fruta, com melhor distribuição de renda ao produtor ao longo do ano; a possibilidade de se conseguir melhores preços, com o produto vendido na entressafra. O uso da irrigação é uma técnica suplementar à poda, além de fundamental para viabilizar a produção de figos de padrão comercial na entressafra.

Neste contexto, o presente trabalho teve como objetivo avaliar o crescimento, a produtividade e a sazonalidade condicionadas pelas épocas de poda e uso ou não da irrigação da figueira 'Roxo de Valinhos'.

\section{MATERIAL E MÉTODOS}

O trabalho foi desenvolvido em Botucatu (SP), cujas coordenadas geográficas, de acordo com TubELIs e SALIBE (1989) são: $22^{\circ} 52^{\prime} 47^{\prime \prime} S, 48^{\circ} 25^{\prime} 12^{\prime \prime} \mathrm{W}$ e altitude de $810 \mathrm{~m}$. De acordo com MARTins (2004), o clima é temperado quente (mesotérmico) com chuvas no verão e seca no inverno. A temperatura média do mês mais frio (julho) é de $17,1^{\circ} \mathrm{C}$ e a do mês mais quente (fevereiro) de $23,3{ }^{\circ} \mathrm{C}$, com precipitação pluvial média anual de $1314 \mathrm{~mm}$. O solo da área foi classificado como Nitossolo Vermelho, segundo os critérios de classificação da EMBRAPA (1999).

Os tratamentos consistiram em quatro diferentes épocas de poda (julho, agosto, setembro e outubro) associadas ou não à irrigação, quando necessário. $\mathrm{O}$ manejo do experimento foi realizado nos ciclos agrícolas de 2004/ 2005 e 2005/ 2006.

O delineamento experimental foi o de parcelas subdivididas, com cinco repetições, sendo as parcelas correspondentes aos tratamentos com e sem irrigação e as subparcelas constituídas pelas podas realizadas em julho, agosto, setembro e outubro de 2004 e 2005. Foram utilizadas 10 plantas por parcela, das quais somente as cinco centrais foram consideradas úteis (PIMENTEL GOMES, 1990).

O experimento foi composto por 420 plantas de figueira cultivar Roxo de Valinhos (Ficus carica L.), com 2 anos e 10 meses de idade, em Julho de 2004, quando se iniciaram os tratamentos de poda e irrigação. A distância de plantio foi de $3 \mathrm{~m}$ entre linhas e $2 \mathrm{~m}$ entre plantas, representando uma densidade de 1660 plantas ha-1. O solo da área experimental foi calcariado e adubado, conforme resultados de análises de solo prévias e seguindo as recomendações técnicas de CAMPO DALL'ORTO et al. (1996). Adubações anuais, tanto químicas como orgânicas, seguiram as recomendações técnicas vigentes e uma produtividade esperada em torno de $10 \mathrm{t} \mathrm{ha}^{-1}$. Os tratamentos fitossanitários e o manejo de plantas daninhas foram feitos na medida em que se fizeram necessários, seguindo as recomendações de Penteado e Franco (1997). 
As plantas foram podadas sempre nos dias 28 a 30 de julho, agosto, setembro ou outubro de 2004 e 2005, com a finalidade de adquirirem a conformação de seis ramos produtivos (Rigitano, 1964; Penteado e FRANCO, 1997). Os seis ramos foram cortados a cerca de 10-15 cm acima da base e em seguida, procedeu-se ao pincelamento dos cortes com pasta bordalesa. Iniciada a brotação, executaram-se desbrotas periódicas, para deixar em cada um dos três ramos adultos, apenas dois brotos vigorosos e bem distribuídos.

Os dados meteorológicos foram fornecidos pelo Departamento de Recursos Naturais da referida faculdade. O balanço hídrico da área experimental está apresentado na figura 1 e os dados da lâmina hídrica aplicada na tabela 1 .

Nos tratamentos em que estava prevista a utilização de irrigação complementar, empregou-se o sistema de irrigação por gotejamento localizado sob copa das plantas. A frequência das irrigações baseou-se em dados de evaporação coletados através do Tanque Classe A, que foi instalado na área experimental. As lâminas de irrigação aplicadas corresponderam às quantidades necessárias para satisfazer $100 \%$ da evapotranspiração de referência (ETo) do tanque classe A. O momento efetivo das irrigações foi determinado em função da reposição da água evaporada no tanque.

Determinou-se a evapotranspiração de referência $(\mathrm{ETo})$ por meio da equação: ETo $=$ Kp $\times$ ECA. ETo é a evapotranspiração de referência, $\mathrm{Kp}$ o coeficiente do tanque classe A e ECA representa a evaporação do tanque classe A (mm). Seguindo as recomendações de Hernandez (1999), adotou-se Kp de 0,75. A evapotranspiração real (ETR) foi calculada pela equação: ETR $=$ Kc $\mathbf{x}$ ETo. ETR representa a evapotranspiração real da cultura, Kc o coeficiente de cultivo e ETo
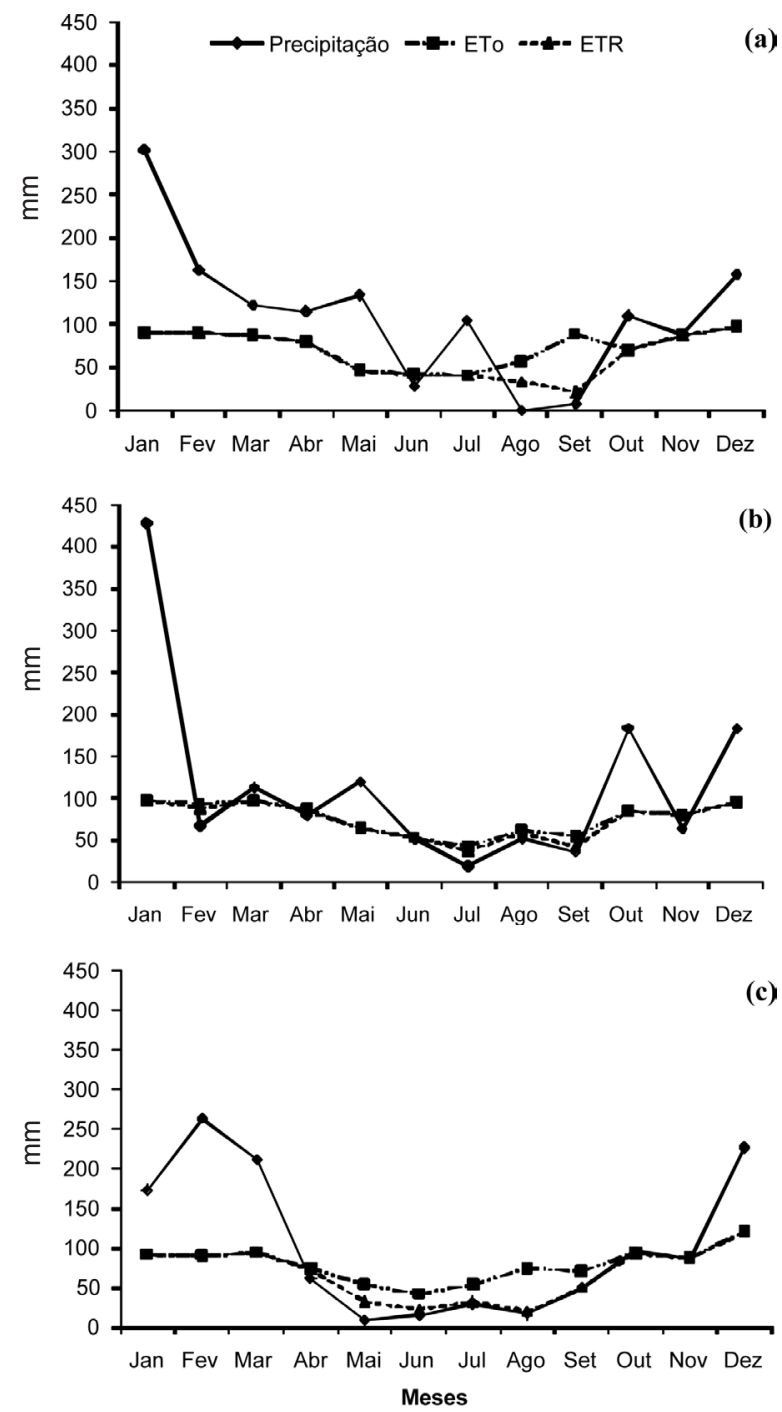

Figura 1. Precipitação pluvial, evapotranspiração de referência (ETo) e evapotranspiração real (ETR) de 2004 (a), 2005 (b) e 2006 (c) em Botucatu (SP).

Tabela 1. Resultados verificados para a lâmina hídrica recebida e lâmina de irrigação aplicada nas plantas de figueira em diferentes épocas de poda e irrigação. Botucatu, 2007

\begin{tabular}{|c|c|c|c|c|c|c|}
\hline Ciclo & $2004 / 2005$ & $2004 / 2005$ & $2004 / 2005$ & $2005 / 2006$ & $2005 / 2006$ & $2005 / 2006$ \\
\hline $\begin{array}{l}\text { Épocas de poda e } \\
\text { irrigação }\end{array}$ & $\begin{array}{l}\text { Irrigação efetuada } \\
\text { no período }\end{array}$ & $\begin{array}{l}\text { Lâmina hídrica } \\
\text { recebida }\end{array}$ & Produção & $\begin{array}{l}\text { Irrigação efetuada } \\
\text { no período }\end{array}$ & $\begin{array}{l}\text { Lâmina hídrica } \\
\text { recebida }\end{array}$ & Produção \\
\hline & \multicolumn{2}{|c|}{$-\mathrm{mm}^{*}$} & g planta $^{-1}$ & \multicolumn{2}{|c|}{$-\mathrm{mm}$} & g planta $^{-1}$ \\
\hline Julho SI & & 1004 & 1428,52 & - & 1282 & 2170,96 \\
\hline Julho CI & 244 & $1248 * *$ & 3093,40 & 231 & $1483^{* *}$ & 3594,52 \\
\hline Agosto SI & - & 1004 & 1516,42 & - & 1230 & 2272,02 \\
\hline Agosto CI & 188 & $1192 * *$ & 3513,78 & 201 & $1431 * *$ & 4110,66 \\
\hline Setemb. SI & - & 1019 & 1398,04 & - & 1181 & 1827,20 \\
\hline Setemb. CI & 133 & $1152 * *$ & 2747,60 & 176 & $1357 * *$ & 3115,34 \\
\hline Outubro SI & - & 939 & 179,90 & - & 1152 & 589,18 \\
\hline Outubro CI & 130 & $1069 * *$ & 642,70 & 165 & $1317 * *$ & 951,54 \\
\hline
\end{tabular}

SI = sem irrigação. CI = com irrigação.

* Quantidade de água recebida pelas plantas entre a poda e a última colheita. ** Valor correspondente à soma das precipitações pluviais e das irrigações efetuadas no período. 
corresponde à evapotranspiração de referência. Adotouse o Kc de 0,47, segundo OlitTA et al. (1979).

Foram instalados gotejadores para cada planta do experimento e sua vazão média foi de $2,34 \mathrm{~L} \mathrm{~h}^{-1}$. Os cálculos da necessidade de reposição de água para a cultura foram efetuados semanalmente, a partir da coleta dos dados do tanque classe A. A quantidade de água aplicada, semanalmente, foi determinada em função do balanço entre a evaporação e a precipitação do período. Detectada a necessidade de suplementação de água para a cultura, bem como a quantidade a ser aplicada, foi estabelecido o número de horas em que o equipamento deveria ficar gotejando.

Os frutos colhidos no experimento estavam no estádio de vez ou quase, quando atingiam massa média de 45 a $50 \mathrm{~g}$, não sendo colhidos completamente graúdos ou inchados (correspondentes aos normalmente vendidos no comércio de frutas ao natural, com massa média entre 85 e $90 \mathrm{~g}$ ). As características avaliadas foram o comprimento $(\mathrm{m})$ e diâmetro $(\mathrm{mm})$ dos ramos primários e secundários, os quais foram mensurados sempre dois dias antes da realização da poda, para cada mês de avaliação. Logo após o corte dos ramos, determinou-se a massa fresca dos ramos provenientes da poda $\left(\mathrm{kg} \mathrm{planta}^{-1}\right)$. A produtividade média de plantas foi estimada considerando-se o número e a massa média de frutos, admitindo-se um estande de 1660 plantas por hectare. Para caracterizar a sazonalidade da figueira, em diferentes meses de poda, computou-se o número de colheitas, as datas de realização da primeira e da última colheita, a concentração do período produtivo e o número de dias do ciclo produtivo, considerando-se a data da poda e da última colheita.

\section{RESULTADOS E DISCUSSÃO}

Os resultados evidenciaram que, com o auxílio da irrigação, ocorreu maior crescimento das plantas, em todas as épocas avaliadas (Tabelas 2, 3, 4 e 5). Esse crescimento correspondeu no ciclo agrícola 2004/2005 a, respectivamente, $8,3 \%$ no comprimento e $10,2 \%$ no diâmetro médio dos ramos primários e 18,2\% no comprimento e $19,2 \%$ no diâmetro médio dos ramos secundários de figueira, quando foi estabelecida a comparação com os tratamentos sem irrigação. No ciclo agrícola 2005/2006, apesar de menores, ocorreram também incrementos no comprimento $(8,3 \%)$ e diâmetro

Tabela 2. Comprimento médio dos ramos primários de figueira, submetida à poda e irrigação. Botucatu, 2007

\begin{tabular}{lcccc}
\hline \multirow{2}{*}{ Irrigação } & \multicolumn{3}{c}{ Épocas } \\
\cline { 2 - 5 } & Julho & Agosto & Setembro & Outubro \\
\hline Ciclo 2004/2005 & $1,06 \mathrm{Ba}$ & $1,08 \mathrm{Ba}$ & $0,90 \mathrm{Ab}$ & $0,82 \mathrm{Ac}$ \\
Sem irrigação & $1,15 \mathrm{Aa}$ & $1,21 \mathrm{Aa}$ & $0,94 \mathrm{Ab}$ & $0,85 \mathrm{Ac}$ \\
Com irrigação & $1,11 \mathrm{a}$ & $1,14 \mathrm{a}$ & $0,92 \mathrm{~b}$ & $0,84 \mathrm{c}$ \\
Média & & & $1,96 \mathrm{~B}$ \\
Ciclo 2005/2006 & $1,41 \mathrm{Ba}$ & $1,48 \mathrm{Ba}$ & $1,30 \mathrm{Bb}$ & $1,08 \mathrm{Ac}$ \\
Sem irrigação & $1,57 \mathrm{Aa}$ & $1,62 \mathrm{Aa}$ & $1,48 \mathrm{Ab}$ & $1,13 \mathrm{Ac}$ \\
Com irrigação & $1,49 \mathrm{~b}$ & $1,55 \mathrm{a}$ & $1,39 \mathrm{c}$ & $1,10 \mathrm{~d}$ \\
Média & & &
\end{tabular}

Médias seguidas de mesma letra, maiúsculas na coluna e minúsculas na linha, em cada ciclo de produção, não diferem entre si pelo teste Tukey, a 5\% de probabilidade. Ciclo 2004/ 2005 - CV (\%) irrigação=3,35; CV (\%) época=4,18. Ciclo 2005/2006 -0,076. CV (\%) irrigação=3,49; CV (\%) época=3,05.

Tabela 3. Diâmetro médio dos ramos primários de figueira, submetida à poda e irrigação. Botucatu, 2007

\begin{tabular}{|c|c|c|c|c|c|}
\hline \multirow{2}{*}{ Irrigação } & \multicolumn{5}{|c|}{ Épocas } \\
\hline & Julho & Agosto & Setembro & Outubro & Média \\
\hline Ciclo 2004/2005 & & & $-\mathrm{mm}-$ & & \\
\hline Sem irrigação & $49,70 \mathrm{Ab}$ & $51,56 \mathrm{Ba}$ & $51,80 \mathrm{Ba}$ & $43,00 \mathrm{Bc}$ & $49,01 \mathrm{~B}$ \\
\hline Com irrigação & $51,10 \mathrm{Ac}$ & $58,62 \mathrm{Aa}$ & $54,52 \mathrm{Ab}$ & $51,72 \mathrm{Ac}$ & $53,99 \mathrm{~A}$ \\
\hline Média & $50,40 \mathrm{c}$ & 55,09 a & $53,16 \mathrm{~b}$ & $47,36 \mathrm{~d}$ & \\
\hline Ciclo 2005/2006 & & & & & \\
\hline Sem irrigação & $60,96 \mathrm{Aa}$ & $61,78 \mathrm{Aa}$ & $60,78 \mathrm{Aa}$ & $57,76 \mathrm{Ab}$ & $60,32 \mathrm{~A}$ \\
\hline Com irrigação & $61,00 \mathrm{Aab}$ & $63,40 \mathrm{Aa}$ & $60,60 \mathrm{Ab}$ & $59,60 \mathrm{Ab}$ & $61,15 \mathrm{~A}$ \\
\hline Média & $60,98 \mathrm{ab}$ & $62,59 \mathrm{a}$ & $60,69 \mathrm{~b}$ & $58,68 \mathrm{c}$ & \\
\hline
\end{tabular}

Médias seguidas de mesma letra, maiúsculas na coluna e minúsculas na linha, em cada ciclo de produção, não diferem entre si pelo teste Tukey, a 5\% de probabilidade. Ciclo 2004/2005 - CV (\%) irrigação=1,40; CV (\%) época=1,94. Ciclo 2005/2006 - CV (\%) irrigação=2,40; CV $(\%)$ época=2,49. 
Tabela 4. Comprimento médio dos ramos secundários de figueira, submetida à poda e irrigação. Botucatu, 2007

\begin{tabular}{|c|c|c|c|c|c|}
\hline \multirow{2}{*}{ Irrigação } & \multicolumn{5}{|c|}{ Épocas } \\
\hline & Julho & Agosto & Setembro & Outubro & Média \\
\hline Ciclo 2004/2005 & - & 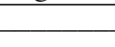 & $-\mathrm{mm}$ & 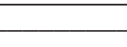 & 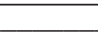 \\
\hline Sem irrigação & $0,35 \mathrm{Bb}$ & $0,43 \mathrm{Ba}$ & $0,33 \mathrm{Bc}$ & $0,21 \mathrm{Bd}$ & $0,33 \mathrm{~B}$ \\
\hline Com irrigação & $0,38 \mathrm{Ab}$ & $0,56 \mathrm{Aa}$ & $0,38 \mathrm{Ab}$ & $0,25 \mathrm{Ac}$ & $0,39 \mathrm{~A}$ \\
\hline Média & $0,37 \mathrm{~b}$ & $0,49 \mathrm{a}$ & $0,36 \mathrm{~b}$ & $0,23 \mathrm{c}$ & \\
\hline Ciclo 2005/2006 & & & & & \\
\hline Sem irrigação & $0,66 \mathrm{Aa}$ & $0,70 \mathrm{Aa}$ & $0,66 \mathrm{Aa}$ & $0,59 \mathrm{Ab}$ & $0,65 \mathrm{~A}$ \\
\hline Com irrigação & $0,63 \mathrm{Ac}$ & $0,74 \mathrm{Ba}$ & $0,69 \mathrm{Ab}$ & $0,62 \mathrm{Ac}$ & $0,67 \mathrm{~A}$ \\
\hline Média & $0,64 \mathrm{~b}$ & $0,72 \mathrm{a}$ & $0,67 \mathrm{~b}$ & $0,60 \mathrm{c}$ & \\
\hline
\end{tabular}

Médias seguidas de mesma letra, maiúsculas na coluna e minúsculas na linha, em cada ciclo de produção, não diferem entre si pelo teste Tukey, a 5\% de probabilidade. Ciclo 2004/ 2005 - 0,019. CV (\%) irrigação=2,03; CV (\%) época=3,43 Ciclo 2005/2006 - CV (\%) irrigação=4,60; CV (\%) época $=4,45$.

Tabela 5. Diâmetro médio dos ramos secundários de figueira, submetida à poda e irrigação. Botucatu, 2007

\begin{tabular}{|c|c|c|c|c|c|}
\hline \multirow{2}{*}{ Irrigação } & \multicolumn{5}{|c|}{ Épocas } \\
\hline & Julho & Agosto & Setembro & Outubro & Média \\
\hline \multicolumn{6}{|l|}{ Ciclo 2004/2005 } \\
\hline Sem irrigação & $11,88 \mathrm{Ba}$ & $11,50 \mathrm{Bab}$ & $11,30 \mathrm{Bb}$ & $9,16 \mathrm{Bc}$ & $10,96 \mathrm{~A}$ \\
\hline Com irrigação & $14,54 \mathrm{Ab}$ & $15,54 \mathrm{Aa}$ & $12,60 \mathrm{Ac}$ & 9,58 Ad & $13,06 \mathrm{~B}$ \\
\hline Média & $13,21 \mathrm{a}$ & $13,52 \mathrm{a}$ & $11,95 \mathrm{~b}$ & $9,37 \mathrm{c}$ & \\
\hline \multicolumn{6}{|l|}{ Ciclo 2005/2006 } \\
\hline Sem irrigação & $16,12 \mathrm{Bab}$ & $16,80 \mathrm{Ba}$ & $16,34 \mathrm{Aab}$ & $15,66 \mathrm{Ab}$ & $16,23 \mathrm{~A}$ \\
\hline Com irrigação & $16,96 \mathrm{Aab}$ & $17,50 \mathrm{Aa}$ & $16,52 \mathrm{Ab}$ & $16,14 \mathrm{Ab}$ & $16,78 \mathrm{~B}$ \\
\hline Média & $16,54 \mathrm{ab}$ & $17,15 \mathrm{a}$ & $16,43 \mathrm{~b}$ & $15,90 \mathrm{~b}$ & \\
\hline
\end{tabular}

Médias seguidas de mesma letra, maiúsculas na coluna e minúsculas na linha, em cada ciclo de produção, não diferem entre si pelo teste Tukey, a 5\% de probabilidade. Ciclo 2004/ 2005 - CV (\%) irrigação=0,92; CV (\%) época=2,11. Ciclo 2005/2006 - CV (\%) irrigação=2,94; CV (\%) época=3,36.

$(1,4 \%)$ dos ramos primários bem como no comprimento $(3,1 \%)$ e diâmetro médio $(3,4 \%)$ dos ramos secundários. Houve, portanto, uma resposta em crescimento das plantas no ciclo 2004/2005 em comparação com o de 2005/2006, uma vez que as plantas estavam anteriormente sendo cultivadas em sequeiro.

Os resultados constantes deste trabalho, estão de acordo com o relato de EzzATT et al. (1975), de que o déficit hídrico paralisa o crescimento das figueiras, e quando acentuado, pode provocar queda intensa de folhas. Também EL-KASSAS (1975) observou maior diâmetro dos ramos e maior número e comprimento dos internódios, o que significa maior comprimento de ramos, em figueiras conduzidas sob irrigação, comparadas às não-irrigadas. Nessa linha de pesquisa, em trabalho realizado por NORBERTO et al. (2001), com o intuito de avaliar a produção e a sazonalidade da figueira, submetida a períodos diferentes de poda e uso da irrigação, em região de clima quente, verificouse que as podas realizadas no período de $15 / 4$ a $15 / 5$, associadas à irrigação, aumentaram em $38 \%$ o comprimento dos ramos e possibilitaram a obtenção da primeira colheita no início da entressafra.
Resultados diferentes e contraditórios em relação à irrigação podem ser observados em situações nas quais não são verificadas deficiências hídricas anuais, ou então, quando ocorrem, podem coincidir com estádios fenológicos da cultura, em que as deficiências são menos sentidas ou visíveis. Assim é que, ao avaliarem lâminas de $0 ; 12,5 \% ; 25,0 \% ; 37,5 \%$ e 50,0\% de reposição da evaporação do tanque classe A, PEDROTTI et al. (1983) não detectaram incrementos significativos no diâmetro do tronco e ramos primários e no diâmetro dos ramos secundários de figueira, no município de Viamão (RS). Segundo os resultados apresentados pelos autores, no período do experimento (setembro/1980 a junho/1981), o déficit hídrico acumulado foi pequeno, correspondendo a lâminas de água aplicadas também pequenas, o que pode explicar a não-ocorrência de diferenças significativas entre os tratamentos de irrigação avaliados.

Nas podas realizadas em agosto de 2004 e 2005, com o emprego da irrigação, obteve-se maior crescimento das plantas, maior comprimento e diâmetro médio dos ramos primários e secundários (Tabelas 2, 3, 4 e 5). As podas realizadas em outubro de 2004 e 2005, apesar de 
Tabela 6. Massa fresca dos ramos de figueira provenientes da poda e irrigação. Botucatu, 2007

\begin{tabular}{lcccc}
\hline Irrigação & \multicolumn{3}{c}{ Épocas } \\
\cline { 2 - 4 } & Julho & Agosto & Setembro & Outubro \\
\hline Ciclo 2004/2005 & $1,03 \mathrm{Aa}$ & $1,16 \mathrm{Aa}$ & $1,01 \mathrm{Aa}$ & $0,94 \mathrm{Aa}$ \\
Sem irrigação & $1,11 \mathrm{Aa}$ & $1,28 \mathrm{Aa}$ & $1,15 \mathrm{Aa}$ & $0,95 \mathrm{Aa}$ \\
Com irrigação & $1,07 \mathrm{a}$ & $1,22 \mathrm{a}$ & $1,08 \mathrm{a}$ & $0,94 \mathrm{a}$ \\
Média & & & $1,06 \mathrm{~A}$ \\
Ciclo 2005/2006 & $1,55 \mathrm{Aa}$ & $1,82 \mathrm{Aa}$ & $1,49 \mathrm{Aa}$ & $1,10 \mathrm{~A}$ \\
Sem irrigação & $1,56 \mathrm{Aa}$ & $1,72 \mathrm{Aa}$ & $1,62 \mathrm{Aa}$ & $1,38 \mathrm{Aa}$ \\
Com irrigação & $1,55 \mathrm{a}$ & $1,77 \mathrm{a}$ & $1,56 \mathrm{a}$ & $1,34 \mathrm{a}$ \\
Média & & & & $1,59 \mathrm{~A}$ \\
\hline
\end{tabular}

Médias seguidas de mesma letra, maiúsculas na coluna e minúsculas na linha, em cada ciclo de produção, não diferem entre si pelo teste Tukey a 5\% de probabilidade. Ciclo 2004/2005 - CV (\%) irrigação=16,33; CV (\%) época= 27,88. Ciclo 2005/2006 - CV (\%) irrigação $=41,62 ; \mathrm{CV}(\%)$ época $=40,89$.

poderem contar com uma boa suplementação hídrica, independentemente da irrigação, não foram favoráveis ao crescimento e desenvolvimento à produção das plantas, sendo inferiores a todas as épocas avaliadas. Essa ocorrência é fundamentada na literatura especializada da área, posto que, Rigitano (1964) e LeONEL e TECCHIO (2004), empregando o recurso de retardar as épocas de poda em figueira nas regiões mais frias, muitas vezes suscetíveis às geadas, que não permitem a antecipação da poda como nas regiões quentes, obtiveram resultados semelhantes aos do presente trabalho, mesmo empregando outros meses de poda.

Os resultados evidenciaram que as plantas podadas em setembro, outubro, novembro e dezembro em regiões mais frias, tiveram crescimento e produções mais baixas. A explicação dos autores, que pode ser também pertinente aos resultados do presente estudo, é que sob essas condições, as plantas passam por frio hibernal, brotando com muita intensidade na primavera e, se, a planta for podada depois, são perdidas muitas reservas. Dessa maneira, fica claro que em regiões de clima mais frio, os estudos comépoca de poda em figueira registram resultados convergentes de que as podas efetuadas após o período hibernal, não demonstram resultados satisfatórios em termos de crescimento de ramos e produção, devido ao fato de serem eliminados os ramos da brotação natural da planta, que ocorreu nos meses anteriores. No entanto, valores mais baixos de crescimento e produção obtidos em épocas de poda menos favoráveis, podem ser compensados por preços maiores obtidos pela venda dos figos na entressafra do mercado produtor, e a viabilidade da execução da poda nessas épocas deve ser avaliada pelo produtor.

Quando se considera a massa fresca total dos ramos podados, verifica-se que não houve variação nas diferentes épocas de poda com ou sem o uso de irrigação (Tabela 6), embora tenhasido verificado maior crescimento de ramos conforme os tratamentos empregados. Esse resultado pode ser explicado, pela pequena diferença entre os intervalos de realização da poda (30 dias). Tal ocorrência também foi relatada no trabalho realizado por GONÇALVES et al. (2006), avaliando diferentes épocas de poda para a produção de figos verdes, em Minas Gerais. Os autores constataram que nas plantas de figueira podadas em março foi obtida maior massa fresca dos ramos, em relação à poda efetuada em setembro, que não diferiu em relação a dezembro e junho. Os autores também relataram que épocas de poda com maior massa verde de poda, induziram maiores produções de frutos. A explicação para esse fato seria que houve maior estímulo ao crescimento com podas realizadas nessas épocas o que teria favorecido a produção pelo aumento no número de nós, nos quais são formados os frutos.

Os dados médios de produtividade observados em 2004/2005 evidenciaram o efeito favorável da irrigação $\left(4,15 \mathrm{t} \mathrm{ha}^{-1}\right)$ em comparação com as áreas sem irrigação $\left(1,87 \mathrm{t} \mathrm{ha}^{-1}\right)$ (Tabela 7). Esses dados representaram aumento em produtividade de $2,28 \mathrm{tha}^{-1}$, correspondendo a um incremento de $56,25 \%$, quando são avaliados todos os meses de poda estudados. Considerando épocas de poda nos tratamentos irrigados, novamente agosto (2004 / 2005) foi o mês mais favorável para a realização desta prática, com a maior produtividade média do ensaio $\left(5,82 \mathrm{t} \mathrm{ha}^{-1}\right)$, superior à reportada por SAMPAIO et al. (1981), na região de Bauru (SP), de 4,5 tha-1.

Sem ouso de irrigação, a produtividade defigueiras podadas em julho, agosto e setembro $(2004 / 2005)$ foi semelhante (média de 2,4 $\mathrm{t} \mathrm{ha}^{-1}$ ). Por outro lado, assim como observado para o crescimento das plantas, a produtividade das figueiras podadas em outubro foi muito baixa, mesmo com o uso de irrigação.

Segundo os relatos de Pereira (1981), Antunes et al. (1997) e ChALfun et al. (1998), a figueira exige clima quente e alta luminosidade no período vegetativo 
Tabela 7. Produtividade média estimada de figueira*, submetida à poda e irrigação. Botucatu, 2007

\begin{tabular}{lcccc}
\hline \multirow{2}{*}{ Irrigação } & \multicolumn{3}{c}{ Épocas } \\
\cline { 2 - 5 } & Julho & Agosto & Setembro & Outubro \\
\hline Ciclo 2004/2005 & $2,37 \mathrm{Ba}$ & $2,52 \mathrm{Ba}$ & $2,32 \mathrm{Ba}$ & $0,30 \mathrm{Bb}$ \\
Sem irrigação & $5,13 \mathrm{Ab}$ & $5,83 \mathrm{Aa}$ & $4,56 \mathrm{Ac}$ & $1,07 \mathrm{Ad}$ \\
Com irrigação & $3,75 \mathrm{~b}$ & $4,17 \mathrm{a}$ & $3,44 \mathrm{~b}$ & $0,68 \mathrm{c}$ \\
Média & & & & $0,98 \mathrm{Bc}$ \\
Ciclo 2005/2006 & $3,60 \mathrm{Ba}$ & $3,77 \mathrm{Ba}$ & $3,03 \mathrm{Bb}$ & $1,06 \mathrm{Ad}$ \\
Sem irrigação & $5,14 \mathrm{Ab}$ & $5,82 \mathrm{Aa}$ & $4,64 \mathrm{Ac}$ & $1,28 \mathrm{~d}$ \\
Com irrigação & $4,78 \mathrm{~b}$ & $5,29 \mathrm{a}$ & $4,10 \mathrm{c}$ & $2,85 \mathrm{~B}$ \\
Média & & & $4,88 \mathrm{~A}$ \\
\hline
\end{tabular}

${ }^{*}$ Considerando-se o estande de 1660 plantas ha- ${ }^{-1}$.

Médias seguidas de mesma letra, maiúsculas na coluna e minúsculas na linha, em cada ciclo de produção, não diferem entre si pelo teste Tukey, a 5\% de probabilidade. Ciclo 2004/2005 - CV (\%) irrigação=7,09; CV (\%) época= 8,89. Ciclo 2005/2006 - CV (\%) irrigação= 8,54; $\mathrm{CV}(\%)$ época $=8,11$.

para proporcionar altos rendimentos. Assim, os autores verificaram que a ocorrência de dias mais curtos e de temperaturas mais baixas, no período inicial de brotação, após a poda realizada em maio, constituíram-se nas causas para as menores taxas de frutificação. Efetuando-se a poda em agosto, a fase de maior crescimento vegetativo e emissão de frutos coincidiu com dias mais longos e quentes, favorecendo a atividade fotossintética e a frutificação. Contudo, podando mais tardiamente, em outubro, as taxas de frutificação reduziram novamente, possivelmente em decorrência da elevada taxa de crescimento vegetativo e redução do ciclo da poda ao início da colheita, resultando em alta concorrência entre os drenos de fotoassimilados, representados pelo crescimento dos ramos e o crescimento e desenvolvimento dos frutos.

No ciclo agrícola 2005/2006, as plantas podadas em julho e agosto proporcionaram produtividades iguais $\left(2,37\right.$ e 2,72 $\left.\mathrm{t} \mathrm{ha}^{-1}\right)$ e o requerimento hídrico foi de $1282 \mathrm{~mm}$ (julho) e $1230 \mathrm{~mm}$ (agosto). A maior produtividade média do ensaio foi de $5,82 \mathrm{t} \mathrm{ha}^{-1}$ de figos maduros, porém não completamente inchados, sendo de $1431 \mathrm{~mm}$ o requerimento hídrico necessário para atingir tal produção (Tabela 1). Os resultados também evidenciaram que, com o uso da irrigação complementar, houve maior número de colheitas e período de produção de frutos em todos os meses de poda, nos dois ciclos agrícolas. Ou seja, além de aumentar a produção de frutos, a irrigação foi mais bem distribuída no período de safra, determinado pelas épocas de poda. A resposta à irrigação foi maior no ciclo agrícola 2004/2005 pelo maior déficit hídrico em relação ao ciclo 2005/2006 (Figura 1). Os resultados apresentados na tabela 1 demonstraram que a dotação hídrica necessária para o aumento da produção da figueira, em Botucatu (SP), não representou muita quantidade de água. $\mathrm{O}$ fator determinante foi o momento correto da aplicação, quando se fez necessária.
As informações contidas na tabela 8 revelam que a poda da figueira em agosto dos ciclos agrícolas 2004/2005 e 2005/2006, com o uso de irrigação, proporcionaram o maior número de colheitas (30 e 45 respectivamente) e o período de concentração da safra estendeu-se de 18/02/2005 a 11/4/2005 totalizando 98 dias em 2004/2005. No ciclo 2005/2006, houve ampliação do período produtivo para 152 dias (10/02 a 20/4/06), justificando o maior número de colheitas realizadas e também, as maiores produções observadas no ensaio. Em julho (2004/2005 e 2005/2006) foi a segunda época de poda com maior número de colheitas, sendo efetuadas no ciclo 2004/2005 sem irrigação 92 colheitas e com irrigação 102 colheitas. No ciclo 2005/2006, realizaram-se 138 colheitas sem irrigação e 151 com irrigação.

Nas podas efetuadas em setembro e outubro (2004/ 2005 e 2005 / 2006) houve diminuição no período de produção de figos (Tabela 8). Com a poda em setembro, no ciclo 2004 / 2005, o período produtivo sem irrigação foi de 38 dias e com irrigação foi de 62 dias, e em 2005/ 2006, de 133 dias com irrigação e 94 dias sem irrigação. Podas efetuadas em outubro induziram o menor período produtivo da figueira; no ciclo 2004/2005 foi de 38 dias sem irrigação e 42 dias com irrigação e em 2005/2006, de 39 dias sem irrigação e 63 dias com irrigação. Nesses dois meses de poda (setembro e outubro), nos dois ciclos agrícolas avaliados, o uso da irrigação proporcionou a antecipação das primeiras colheitas e aumento no período produtivo, pois o período de colheita desses tratamentos ocorreu em março e abril, nos quais já havia um início de deficiência hídrica.

\section{CONCLUSÕES}

1. A irrigação favorece o crescimento das plantas e proporciona produtividades superiores, independentemente da época de realização da poda. 
Tabela 8. Período produtivo, número total de colheitas, data do início e do final e época de maior produção de frutos de figueira, submetida à poda e irrigação. Botucatu, 2007

\begin{tabular}{|c|c|c|c|c|c|}
\hline Época e irrigação & Número de colheitas & Início das Colheitas & Final das Colheitas & Concentração da produção & Período produtivo \\
\hline Ciclo 2004/2005 & & & - dias & & \\
\hline Julho SI & 23 & $6 / 1 / 05$ & $8 / 4 / 05$ & $25 / 1$ a $17 / 3 / 05$ & 92 \\
\hline Julho CI & 28 & $6 / 1 / 05$ & $18 / 4 / 05$ & $25 / 1$ a $18 / 4$ & 102 \\
\hline Agosto SI & 26 & $17 / 1 / 05$ & $18 / 4 / 05$ & $4 / 2$ a $4 / 4 / 05$ & 91 \\
\hline Agosto CI & 30 & $17 / 1 / 05$ & $25 / 4 / 05$ & $18 / 2$ a $11 / 4 / 05$ & 98 \\
\hline Setembro SI & 09 & $13 / 3 / 05$ & $5 / 5 / 05$ & $15 / 4$ a $21 / 4 / 05$ & 53 \\
\hline Setembro CI & 14 & $4 / 3 / 05$ & $15 / 5 / 05$ & $17 / 3$ a $18 / 4 / 05$ & 62 \\
\hline Outubro SI & 04 & $10 / 4 / 05$ & $18 / 5 / 05$ & $18 / 4 / 05$ & 38 \\
\hline Outubro CI & 07 & $24 / 3 / 05$ & $5 / 5 / 05$ & $15 / 4 / 05$ & 42 \\
\hline \multicolumn{6}{|l|}{ Ciclo 2005/2006 } \\
\hline Julho SI & 35 & $18 / 12 / 05$ & $05 / 5 / 06$ & $15 / 1$ a $21 / 3 / 06$ & 138 \\
\hline Julho CI & 41 & $18 / 12 / 05$ & $18 / 5 / 06$ & $15 / 1$ a $12 / 4 / 06$ & 151 \\
\hline Agosto SI & 38 & $27 / 12 / 05$ & $8 / 5 / 06 /$ & $7 / 2$ a 10/4/06 & 132 \\
\hline Agosto CI & 45 & $27 / 12 / 05$ & $28 / 5 / 06$ & $10 / 2$ a $20 / 4 / 06$ & 152 \\
\hline Setembro SI & 16 & $6 / 1 / 06$ & $19 / 5 / 06$ & $10 / 4$ a $30 / 4 / 06$ & 94 \\
\hline Setembro CI & 28 & 20/1/06 & $19 / 5 / 06$ & $12 / 3$ a $30 / 4 / 06$ & 133 \\
\hline Outubro SI & 05 & 29/4/06 & $7 / 6 / 06$ & $15 / 4$ a $30 / 4 / 06$ & 39 \\
\hline Outubro CI & 10 & $10 / 4 / 06$ & $1206 / 06$ & $10 / 4$ a $30 / 4 / 06$ & 63 \\
\hline
\end{tabular}

$\mathrm{SI}=$ sem irrigação. $\mathrm{CI}=$ com irrigação.

O efeito benéfico da irrigação também fica evidenciado através do aumento do número de colheitas, em todas as épocas, havendo melhor distribuição da produção no período de safras.

2. A poda dos seis ramos frutíferos da figueira no fim de agosto (2005/2006), com irrigação, propicia a maior produtividade média do ensaio, sendo de 5,82 $\mathrm{t}$ ha $^{-1}$ de figos maduros, porém não completamente inchados. $\mathrm{O}$ requerimento hídrico necessário para atingir tal produção é de $1431 \mathrm{~mm}$.

\section{AGRADECIMENTOS}

À Fundação de Amparo à Pesquisa do Estado de São Paulo (FAPESP). Processo N. ${ }^{\circ} 03$ / 13766-0.

\section{REFERÊNCIAS}

ANTUNES L.E.C.; ABRAHÃO, E.; SILVA, V.J. Caracterização da cultura da figueira no estado de Minas Gerais. Informe Agropecuário, v.18, p.43-44, 1997.

BRIGHENTI, E. Influência do número de ramos básicos e da irrigação na produção de figos verdes (Ficus carica L.) da cultivar Roxo de Valinhos. 1980. Tese (Mestrado. Agronomia - Fitotecnia). Faculdade de Agronomia, UFPel, Pelotas, 1980.

CAMPO DALL'ORTO, F.A.; CANTARELA, H.; RAIJ, B.V.; PIZA JÚNIOR, C.T. Frutas de clima temperado: II. Figo, maçã, marmelo, pêra e pêssego em pomar compacto. In: RAIJ. B.van et al. (Ed.). Recomendações de adubação e calagem para o
Estado de São Paulo. 2.ed. Campinas: Instituto Agronômico e Fundação IAC, 1996. p.139-140.

CHALFUN, N.N.J.; HOFFMANN, A.; PASQUAL, M. Frutíferas de clima temperado. Lavras: UFLA/FAEPE, 1998. v.7, 304p.

CORRÊA, L.S.; SANTOS, S.C. Condução e tratos culturais da figueira. In: CORREAA, L. de S., BOLIANI, A.C. Cultura da figueira: do plantio à comercialização. Ilha Solteira: FUNEP/ FAPESP, 1999. p.51-68.

EL-KASSAS, S.E. Effect of soil moisture levels and nitrogen fertilization on yield, shoot growth and leaf composition on fig trees. American Agricultural Science, v.4, p.155-186, 1975.

EMBRAPA. Centro Nacional de Pesquisa de Solos. Sistema Brasileiro de Classificação de Solos. Rio de Janeiro, 1999. 412p.

EZZAT, A.H.; NAGUIB, M.; ELMENCHAWY, E.A.; MITWALLI, S.; HASSAN, G.F. Effect of irrigation on the growth and fruiting of 'Sultani' fig trees in dry farming areas. Agriculture Research Review, v.53, p.8-15, 1975.

GONÇALVES, C.AA.; LIMA, L.C.O.; LOPES, P.S.N.; SOUZA, M.T. Poda e sistemas de condução na produção de figos verdes. Pesquisa Agropecuária Brasileira, v.41, p.995-961, 2006.

HERNANDEZ, F.B.T. Irrigação na figueira. In: CORREA, L.S.; BOLIANI, A.C. Cultura da figueira do plantio à comercialização. Ilha Solteira: FUNEP, 1999. p.87-113. 
LEONEL, S.; TECCHIO, M.A. Avaliação de épocas de poda e doses de cianamida hidrogenada em figueira, cultivada no município de Botucatu/SP. In: CONGRESSO BRASILEIRO DE FRUTICULTURA, 18., 2004, Florianópolis. Anais... Florianópolis: Universidade Federal de Santa Catarina, 2004. (Cd-rom)

MAIORANO, J.A.; ANTUNES, J.E.C.; REGINA, M.A.; ABRAHÃO, E.; PEREIRA, A.F. Botânica e caracterização de cultivares de figueira. Informe Agropecuário, v.18, p.22-24, 1997.

MARTINS, D. Botucatu é realmente a cidade dos bons ares. Jornal da Faculdade de Ciências Agronômicas, p.3-4, 2004.

NORBERTO, P.M.; CHALFUN, N.N.J.; PASQUAL, M.; VEIGA, R.D.; MOTA, J.H. Efeito de época de poda, cianamida hidrogenada e irrigação na produção antecipada de figos verdes. Pesquisa Agropecuária Brasileira, v.36, p.1363-1369, 2001.

OLITTA, A.F.L.; SAMPAIO, V.R.; BARBIN, D. Estudo da lâmina e freqüência de irrigação por gotejo na cultura do figo. O Solo, v.71, p.9-22, 1979.

PEDROTTI, E.L.; MANICA, I.; BELTRAME, L.F.S. Níveis de irrigação, crescimento das plantas e concentração de nutrientes nas folhas de figueira (Fícus carica L.) 'Roxo de Valinhos'. Agronomia Sulriograndense, v.19, p.103-116, 1983.

PENTEADO, S.R.; FRANCO, J.A.M. Figo (Fícus carica L.). Manual técnico das culturas. Campinas: SAA/CATI/DCT, 1997. p.127-139.

PEREIRA, F.M. Cultura da figueira. Piracicaba: Livroceres, 1981. 73p.

PIMENTEL GOMES, F. Curso de estatística experimental. 13.ed. Piracicaba: Nobel, 1990. 468 p.

RIGITANO, O. Instruções para a cultura da figueira. Campinas: SAA/IAC, 1964. 30p. v.3, Mimeografado. (Boletim Técnico n. ${ }^{\circ}$ 146)

SAMPAIO, V.R.; OLITTA, A.F.; OLIVEIRA, A.F. Efeitos de épocas de poda na produção de figo irrigado por gotejamento. Anais da Escola Superior de Agricultura Luiz de Queiroz, v.38, p.847-857, 1981

TUBELIS, A.; SALIBE, A.A. Relações entre produção de laranjeira 'Hamlin' e as precipitações mensais no altiplano de Botucatu. Pesquisa Agropecuária Brasileira, v.24, p. 801-806, 1989. 